Article

\title{
Spatio-Temporal Analysis of Population-Land-Economic Urbanization and Its Impact on Urban Carbon Emissions in Shandong Province, China
}

\author{
Kui Liu ${ }^{1}{ }^{1}$, Jian Wang ${ }^{2, *}$, Xiang Kang ${ }^{1}$, Jingming Liu ${ }^{1}$, Zheyi Xia ${ }^{2}{ }^{\circledR}$, Kai Du ${ }^{3}$ and Xuexin Zhu ${ }^{4}$ \\ 1 School of Public Policy and Administration, Xi'an Jiaotong University, Xi'an 710049, China; \\ kui.phd@stu.xjtu.edu.cn (K.L.); kangxiang9523@stu.xjtu.edu.cn (X.K.); jimmyliu1993@stu.xjtu.edu.cn (J.L.) \\ 2 College of Land Science and Technology, China Agricultural University, Beijing 100193, China; \\ xiazheyi@cau.edu.cn \\ 3 Administration and Management Institute of Ministry of Agriculture and Rural Affairs, Beijing 102208, China; \\ dkphd@cau.edu.cn \\ 4 School of Management Engineering, Qingdao University of Technology, Qingdao 266520, China; \\ zhuxuexin@qtech.edu.cn \\ * Correspondence: wangjian@cau.edu.cn; Tel.: +86-010-6273-4069
}

check for updates

Citation: Liu, K.; Wang, J.; Kang, X.; Liu, J.; Xia, Z.; Du, K.; Zhu, X. Spatio-Temporal Analysis of Population-Land-Economic Urbanization and Its Impact on Urban Carbon Emissions in Shandong Province, China. Land 2022, 11, 266. https://doi.org/ 10.3390/land11020266

Academic Editor: Baojie He

Received: 20 January 2022

Accepted: 4 February 2022

Published: 10 February 2022

Publisher's Note: MDPI stays neutral with regard to jurisdictional claims in published maps and institutional affiliations.

Copyright: (C) 2022 by the authors. Licensee MDPI, Basel, Switzerland. This article is an open access article distributed under the terms and conditions of the Creative Commons Attribution (CC BY) license (https:// creativecommons.org/licenses/by/ $4.0 /)$.

\begin{abstract}
New-type urbanization is a dynamic process composed of numerous elements and multiple subsystems. Coordination and coherence of various subsystems are critical for promoting urban-rural integration and regional synergistic development and will have a complicated impact on sustainable development in the trade-off between socioeconomic growth and environmental conservation. This paper theorized the interconnected and mutually influential coupling coordination relationship between population-land-economic urbanization (PLEU) and the mechanism by which this relationship affects urban carbon emissions. The Wavelet Neural Network (WNN), Coupling Coordination Degree model, and econometric model were used to reveal this relationship and mechanism. A total of 17 cities in Shandong Province, China, were used as study subjects for empirical examination. The results show that the level of PLEU in Shandong was significantly improved from 2007 to 2016, but the gap between cities tended to further expand. The 17 cities gradually got rid of the antagonistic disorder issue of the coupling coordination relationship of PLEU from 2007 to 2016, spatially showing the agglomeration characteristics with Qingdao and Jinan as the core, respectively. The influence of the coupling coordination degree of PLEU on urban carbon emissions presents an inverted, U-shaped characteristic, that is, the total urban carbon emissions will first increase and then decrease as the improvement of the coupling coordination relationship of PLEU. China's new-type urbanization has provided an efficient solution to sustainable development, namely planning and designing at the highest strategic level to establish scientific goals. This new-type urbanization strategy could provide an effective alternative for other emerging countries worldwide, for addressing the challenges to sustainable development.
\end{abstract}

Keywords: population-land-economic urbanization (PLEU); spatio-temporal characteristics; urban carbon emissions; wavelet neural network (WNN); coupling coordination relationship; econometric model

\section{Introduction}

Urbanization is an inevitable tendency accompanying the industrialization and modernization of human society and it is also an impetus to stimulating sustainable regional economic growth and realizing optimal allocation of resource elements [1]. As the core of global economic growth, cities are complexes formed by the interaction of various human activities and natural factors [2]. It is predicted that more than $65 \%$ of the global population will live in and near cities by 2050 and the urban population in China will exceed 75\% [3]. 
Urbanization is a dynamic evolutionary process that includes multiple dimensions of population, land, and economy in which population agglomeration is the external manifestation of the flow of resource factors to cities, and economic growth is one of the core goals of urbanization and land is the basic carrier to support population agglomeration and economic growth. Not only does urbanization attract rural populations, but it also mobilizes and allocates resources through the interaction of the population, land, and economy as three subsystems, thereby improving the social system. However, empirical experience has demonstrated that factor-intensive urbanization paths have resulted in critical habitat degradation challenges [4]. For example, urbanization has crowded out enormous amounts of arable land, leading to changes in soil carbon stocks, which ultimately has an impact on global warming [5]. This prompted policymakers and scholars to consider the following themes: How do the population, land, and economy interact in the urbanization process? What are the consequences for the global sustainable development of those mechanisms?

China is the largest developing country and the second-largest economy in the world. Taking advantage of sufficiency and inexpensive surplus rural labor and the government's capability to allocate resources, China has experienced dramatic growth in urbanization and industrialization in nearly four decades since the reform and opening up [6]. From 1978 to 2016, more than 500 million people migrated from rural to urban areas; the population of urban residents increased from 170 million to 820 million, the urbanization rate annually increased by $1.08 \%$, and the number of cities increased from 193 to 658 [7]. Meanwhile, the burgeoning urban population has raised the demand for urban land which increased by an average annual of $1278.93 \mathrm{~km}^{2}$ in urban construction land between 1981 and 2016 and reached 52,761.30 $\mathrm{km}^{2}$ [7]. Although urbanization has fueled rapid economic growth in China, this crude development pattern was centered on land by supplying industrial land at low prices and commercial and residential land at high prices. This development pattern has not only resulted in socioeconomic issues, such as imbalance of human-land urbanization, inefficient urban land use, and difficulties for large numbers of agricultural migrants to integrate into urban society $[8,9]$, but has also seriously harmed the environment and incurred massive environmental expenditures [10].

In response to sustainable development challenges, such as economic growth slowdown and habitat degradation, the Chinese government launched the new-type urbanization strategy in 2014, which attempts to modify the traditional urban development pattern [11]. Compared with traditional urbanization, new-type urbanization refers to a human-oriented urbanization pattern that emphasizes the orderly coordination of population, land, and economic subsystems and achieves low-carbon transformation through the interaction of industrial upgrading, employment transfer, and population agglomeration, to meet sustainable development challenges [12]. The key point to the benign development of new-type urbanization is to realize the coordination and orderliness between populationland-economy subsystems, to balance socioeconomic development and environmental conservation, and to optimize elements input and resource allocation. Many existing theoretical studies and practices proved that a significant interaction relationship exists between population-land-economy urbanization (PLEU), which is influenced by institutional foundations, governmental decisions, elements allocation, industrial structure, and economic layout $[13,14]$. However, theoretical and empirical analyses of the coupling relationship between PLEU and its impact on global sustainable development, specifically urban carbon emissions, are still absent. This paper aims to analyze the relationship between different subsystems of PLEU and to investigate its impact on urban carbon emissions.

\section{Literature Review}

In recent years, many scholars focused on the research of the relationship between population, land, and the economy in the context of growing urbanization. Mainstream studies on this topic have generally addressed the following three aspects. The first aspect is the study of China's new-type urbanization strategy. The themes of these studies include theoretical discussion on new-type urbanization [15], financing risks and financial system 
establishment of new-type urbanization [16,17], green and healthy development of newtype urbanization [18], new-type urbanization and regional synergistic development [19], and global impacts of new-type urbanization [20]. The second aspect is the tendency of PLEU and the interaction between them, including population migration and urban-rural integration [21], the impact of urbanization on residents' health [22], the causal relationship between population urbanization and land urbanization [23], and the mechanism of population urbanization and economic growth [24]. In addition, the impact of population growth and urbanization on agricultural risk [25] and monitoring of urban land expansion using remote sensing technology [26] are also key research themes. The third aspect is the impact of the coupling coordination relationship of PLEU on sustainable development goals. The themes of these studies include the coupling coordination relationship of PLEU and its influencing factors [14], mechanism analysis of the impact of this relationship on the environment [27], the impact on urban carbon emissions [28], and the influence analysis on regional economic growth [29].

Since the new-type urbanization strategy has been proposed, scholars from China have conducted extensive argumentative analysis on it [30,31], and analyzed the development path of new-type urbanization from multiple dimensions [32]. Existing studies analyzed the interaction of relationships of urbanization subsystems, such as population, land, and economy using the Entropy Weight method [33], TOPSIS evaluation method [34], SVAR model [35], and coupling coordination degree [36] to provide policy recommendations for the future urbanization path of China. Meanwhile, studies have increasingly begun to focus on the factors that influence the coupling coordination relationship of PLEU, aiming to investigate effective solutions to achieve the coupling coordination development of PLEU. The majority of the studies employed Exploratory Spatial Data Analysis and Econometric modeling to confirm the incongruity of PLEU, such as land urbanization occurring faster than population urbanization in the past period of the urbanization process in China [37]. Several factors, such as urban-rural dualism, degree of market cultivation, geographical location, and foreign trade are critical factors contributing to these issues [38,39].

The coupling coordination relationship of PLEU refers to the dynamic evolution characteristics of the urban population, land, and economy exhibiting harmony and order in new-type urbanization, which decreases the negative externalities in the urbanization process, achieves low-carbon goals, and green economic growth [32]. Population is the core of new-type urbanization. Affected by many factors, such as the urban-rural income gap and uneven distribution of public services, the population will migrate frequently between urban and rural areas. The urban-rural population migration contributes to the spatial allocation of resource factors, which changes the urban-rural economic structure. Meanwhile, benefiting from the circular cumulative causal effect, the upgrading of industrial structure drives urban economic growth and attracts more population and resources to agglomerate in cities [40]. In the whole course, land is the basic carrier of new-type urbanization. In rural areas, arable land and residential land are family capital on which farmers rely for their livelihood. In cities, construction land can be used for residential, industrial, commercial, and transportation purposes, which assists cities to accommodate larger populations and industries. Urban-rural migration reduces the demand for arable land and residential land and increases the amount of urban construction land. To sum up, PLEU is the key component of new-type urbanization and the interaction among three parties changes the demographic structure, economic structure, and land usage structure of cities through the above-mentioned interrelationship.

Existing literature demonstrated that China's new-type urbanization strategy implied that the government is determined to redirect its policy from the old rural-urban dual structure to a more harmonious and more productive life for addressing the tremendous problems of transferring agricultural populations to cities and helping them obtain equal public services [12]. Notwithstanding the distinctive Chinese characteristics of new-type urbanization, its human-oriented mindset can provide meaningful implications for countries and governments worldwide that are currently trapped in the middle-income trap. 
Simultaneously, one of the main goals of new-type urbanization is to realize sustainable development, which requires coordination of the interactions between population, land, and the economy [15]. The uncoordinated development among PLEU will cause a series of long-term, negative impacts on the socioeconomic and natural environment. For example, the relationship of the uncoordinated PLEU contributes greatly to the increase of urban PM2.5 content [41].

By reviewing existing literature, it is found that many studies have analyzed the coupling coordination relationship of PLEU and its affecting factors from theoretical and practical perspectives. However, some gaps remained in these studies. Firstly, in research methodology, traditional methods usually measured the level of new-type urbanization from a single dimension [42], lacking accurate measurement and comprehensive analysis. Secondly, existing studies have concentrated on the interaction of PLEU and influential factors but have paid less attention to the effect of PLEU on sustainable development goals, especially on urban carbon emissions. Consequently, by analyzing the interaction mechanisms of PLEU, this paper aims to investigate how the coupling coordination of PLEU will affect urban carbon emissions that will, to some certain extent, make up for these gaps in knowledge.

The rest of the article is structured as follows. The interaction and interrelated mechanism of effect among PLEU are explored in the following section. The study area, methods, and data sources are presented in Section 4. The main results of the spatio-temporal coupling characteristics of PLEU in Shandong Province and the econometric analysis of its impact on urban carbon emissions are reported in Section 5. The discussions are discussed in Section 6. The conclusions are reported in the final section.

\section{Analytical Framework}

3.1. A Framework for Analyzing the Relationship between PLEU Coupling Coordination Degree and Urban Carbon Emissions

The growth pole theory holds that economic growth is unbalanced, which means that within a certain period, the dominant and driving sectors propel regional economic growth into rapid development by above-average growth and exert their influence through the close connection between various sectors [43]. New-type urbanization is a complicated system composed of various elements and subsystems, which is a dynamic course of transforming non-urban construction land into urban construction land, concentrated population flowing to cities, industrial agglomeration, and optimal allocation of elements resources. Coordination and coherence among various subsystems should be maintained when new-types urbanization evolves [20]. The population is the core of new-type urbanization. Rapid economic development attracts surplus rural labor to cities, which fuels further economic expansion. In cities, rural migrants have access to higher incomes and better-quality public services. Meanwhile, land serves as a vehicle for population and economic urbanization, supporting the growing population and elevating the economic status of cities [13].

The theory of unbalanced development argues that the unequal development of an interregional economy is inevitable. However, the "polarization effect" and "trickle-down effect" will form in the process of economic development to make the regional differences show an "inverted U-shaped" change, which first expands and then decreases [44]. The discrepancies in population, resource endowment, governmental decision-making, and the economic base of regionals will cause the level and quality of new-type urbanization development to vary from region to region, showing complex internal clustering and spatial differentiation between regions. The level of new-type urbanization subsystems within regions also varies from high to low and the development of each subsystem is seriously unbalanced between and within regions [45]. However, over time, new-type urbanization development is influenced by the "trickle-down effect", which could contribute to regional balance and coordination. 
Figure 1 depicts the interplay of PLEU and its mechanism of contribution to urban carbon emissions. New-type urbanization promotes urban-rural integration and regional synergy by an optimal combination of elements input and resource allocation and will balance socioeconomic development and urban carbon emissions. Primarily, one of the overall goals of new-type urbanization is to establish an ecological civilization and a harmonious coexistence between humanity and nature, which necessitates that new-type urbanization confronts the environmental consequences caused by urban development and implements appropriate measures to address the challenges of sustainable development, such as nature-based solutions (NBS) [46]. Secondly, the crucial pathway to promoting the development of new-type urbanization lies in coupling coordinating the interactions among various subsystems and relying on reform and innovation to promote technological advancement and realize the optimal combination of natural input and resource allocation, at the expense of ecological and environmental concerns, such as an increase in urban carbon emissions. Nevertheless, as the coupling and coordination relationship of PLEU continuously improves, the ecological and environmental challenges will be effectively solved, and total urban carbon emissions will undoubtedly reach a peak and gradually decline. The reason is that when PLEU is coordinated well, urban land will be used efficiently, and the population and resources will be optimally allocated spatially. At the same time, technological innovation will probably drive green economic growth.

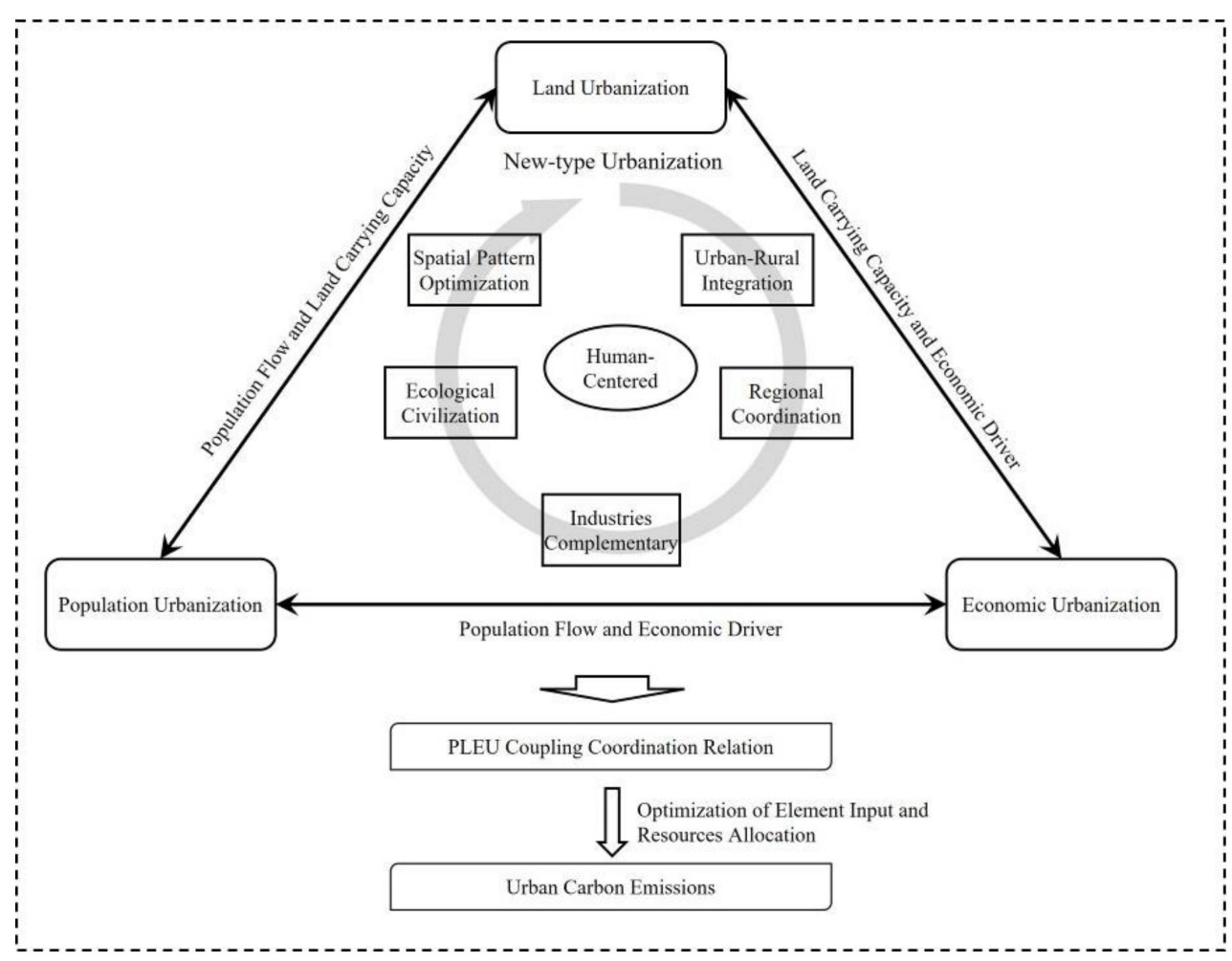

Figure 1. Theoretical mechanism of coupling coordination of PLEU and urban carbon emissions.

In short, the benign development of new-type urbanization is more likely to occur when PLEU interacts in an orderly and coordinated manner. Reaching the coupling coordination of PLEU requires the optimal combination of elements input and resource allocation and has a complex impact on urban carbon emissions.

\subsection{PLEU Evaluation Indicators System}

New-type urbanization accomplishes urban-rural integration and regional synergy by the coordination of PLEU. Population urbanization is mainly manifested as ruralurban migration, which relies on a better employment environment and higher income levels in cities to achieve higher income growth in the short term while being invested 
in economic production as a labor element. During this period, the urban household and resident populations continuously increased and urban per capita disposable income rose significantly. The economy, which is the driving force of urbanization, manifests as increased GDP and output of secondary and tertiary industries and forms a more outwardlooking economic structure in the process of industrial upgrading. Urban population increasing and industrial upgrading require more land supply, which is manifested in the expansion of urban construction land and efficient and intensive land usage. Considering the connotations of new-type urbanization, the evaluation indicators system of PLEU was constructed with the principles of relevance, objectivity, and accessibility based on studies by many scholars $[47,48]$ for purposes of being able to measure the level of PLEU more scientifically and accurately (Table 1).

Table 1. PLEU evaluation indicators system.

\begin{tabular}{|c|c|c|c|}
\hline $\begin{array}{l}\text { New-Type Urbanization } \\
\text { Subsystems }\end{array}$ & Indexes & Units & Index Significance \\
\hline \multirow{4}{*}{ Population urbanization } & $\begin{array}{l}\text { The proportion of the } \\
\text { non-farm population in cities }\end{array}$ & $\%$ & $\begin{array}{l}\text { Key demographic indicators for } \\
\text { measuring urbanization }\end{array}$ \\
\hline & The average wage of employees & yuan & $\begin{array}{l}\text { Imply the quality of the urban } \\
\text { population }\end{array}$ \\
\hline & Urban registered unemployment rate & $\%$ & $\begin{array}{l}\text { The implied scale of the city's } \\
\text { employed population }\end{array}$ \\
\hline & Per capita disposable income & yuan & $\begin{array}{c}\text { Reflects household income and } \\
\text { living costs }\end{array}$ \\
\hline \multirow{4}{*}{$\begin{array}{c}\text { Land } \\
\text { urbanization }\end{array}$} & $\begin{array}{l}\text { The proportion of urban } \\
\text { construction land }\end{array}$ & $\%$ & $\begin{array}{l}\text { Key statistical indicators of urban } \\
\text { land use }\end{array}$ \\
\hline & $\begin{array}{l}\text { Government revenue } \\
\text { averaged overland }\end{array}$ & yuan $/ \mathrm{hm}^{2}$ & $\begin{array}{l}\text { Reflects government's land } \\
\text { financing ability }\end{array}$ \\
\hline & $\begin{array}{l}\text { Investment in fixed assets } \\
\text { averaged overland }\end{array}$ & yuan $/ \mathrm{hm}^{2}$ & $\begin{array}{l}\text { Reflects degree of land conservation } \\
\text { and intensification }\end{array}$ \\
\hline & Per capita road & $\mathrm{m}^{2} /$ person & $\begin{array}{l}\text { The element that implies land } \\
\text { circulation ability }\end{array}$ \\
\hline \multirow{4}{*}{ Economic urbanization } & $\begin{array}{l}\text { Ten thousand GDP } \\
\text { energy consumption }\end{array}$ & $\begin{array}{c}\text { ton } \\
\mathrm{SCE} / 10,000 \text { yuan }\end{array}$ & $\begin{array}{l}\text { Reflects the level of green } \\
\text { economic growth }\end{array}$ \\
\hline & GDP growth rate & $\%$ & $\begin{array}{l}\text { Reflects the level of } \\
\text { economic growth }\end{array}$ \\
\hline & $\begin{array}{l}\text { The ratio of secondary and } \\
\text { tertiary industries }\end{array}$ & $\%$ & $\begin{array}{l}\text { Reflects the structure of } \\
\text { economic growth }\end{array}$ \\
\hline & Actual foreign investment & yuan & $\begin{array}{l}\text { Reflects economic growth of foreign } \\
\text { trade dependence }\end{array}$ \\
\hline
\end{tabular}

\section{Materials and Methods}

\subsection{Study Area}

Shandong province is located in the eastern part of the North China Plain and is one of fourteen coastal provinces, with 17 cities under its jurisdiction, including Jinan and Qingdao. The western part of Shandong is respectively bordered by Hebei, Henan, Anhui, and Jiangsu Province (Figure 2). Due to the tourist resort of Mount Tai located in the middle, the overall topography of Shandong exhibits geomorphic features of mountainous prominence in the central, low-lying, and flat terrain in the southwest and northwest, and gently undulating hills in the east. Relevant statistics show that the population urbanization rate in Shandong rapidly increased from $46.75 \%$ in 2007 to $59.02 \%$ in 2016, with more than a $25 \%$ increase. Comparatively, urban construction land has expanded more rapidly, from $3023 \mathrm{~km}^{2}$ in 2007 to $4540 \mathrm{~km}^{2}$ in 2016, with a growth rate of 50.18\% [7]. As the third-largest province of GDP in China, Shandong has developed county economy and sound industrial categories, as well as more balanced inter-regional development. This showed different development routes of urbanization and industrialization from Guangdong and Jiangsu, while the latter two being the first and second provinces with the largest GDP [49]. However, 
this pattern has also brought about its low-factor productivity, with the land urbanization rate being significantly higher than the population urbanization rate, which makes it difficult to fully realize the dominant function of urban factor aggregation and economic growth and faces severe environmental consequences [50]. Currently, local governments in Shandong actively embrace new-type urbanization strategies in an attempt to restrain the previously uncontrolled rate of urban land expansion, straddle the middle-income trap by industrial upgrading and economic restructuring, and eliminate negative environmental externalities caused by urban development. This provides a typical region for exploring the spatio-temporal coupling characteristics of PLEU and its influence on urban carbon emissions. The results can provide theoretical references for balancing regional sustainable development and environmental conservation.

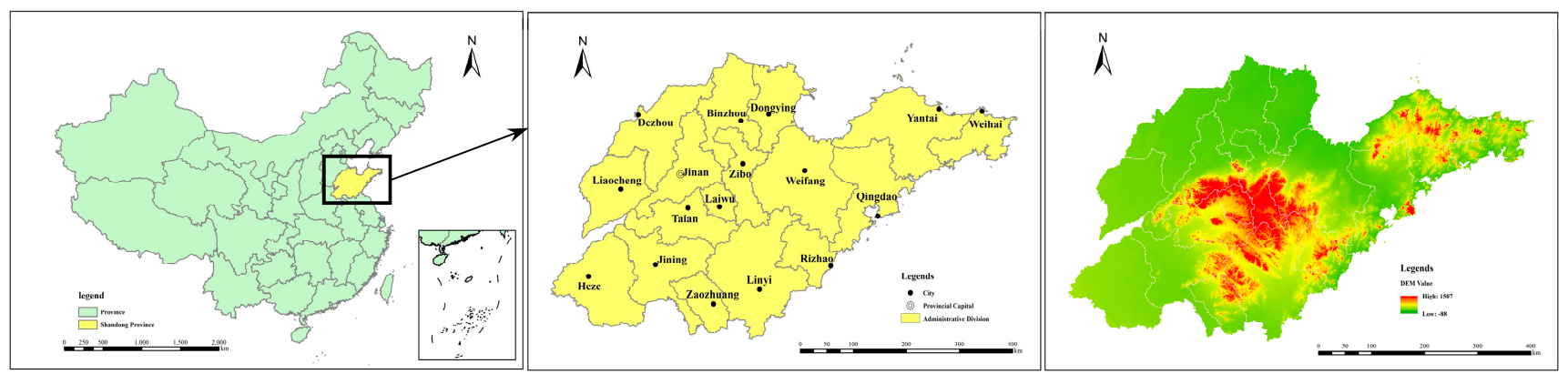

Figure 2. Location of Shandong province, China.

\subsection{Methodology}

\subsubsection{The Wavelet Neural Network Model for Evaluating the Level of PLEU}

Wavelet Neural Network (WNN) is an artificial neural network model based on the improvement of wavelet analysis [51]. WNN uses the Wavelet Function as an activation function rather than the Sigmoid Function and establishes the connection between wavelet transform and network coefficient via affine transformation. The corresponding weights from the input layer to the hidden layer and the threshold value of the hidden layer are replaced with the scaling factor and time translation factor of the Wavelet Function respectively, to construct the nonlinear function between the optimal approximation variables and, finally, calculate the attribute value of the evaluation object. Compared with conventional evaluation approaches, the WNN method can produce more objective and accurate, steady results by adaptive learning [51,52]. PLEU is influenced by a variety of socioeconomic and natural endowment characteristics and traditional evaluation methods have difficulty capturing the intricate interplay of these factors. Therefore, WNN was applied to evaluate the level to which Shandong's PLEU has developed in this paper. The specific model [53] is as follows:

$$
\begin{aligned}
h\left(\frac{x-b}{a}\right) & =\cos \left(1.75 \times \frac{x-b}{a}\right) e^{\left(-0.5 \times\left(\frac{x-b}{a}\right)^{2}\right)} \\
a_{k}^{\text {new }} & =a_{k}^{\text {old }}+\eta \sum_{m=1}^{p} \delta_{a_{k}}+\lambda \Delta a_{k}^{\text {old }} \\
b_{k}^{\text {new }} & =a_{k}^{\text {old }}+\eta \sum_{m=1}^{p} \delta_{b_{k}}+\lambda \Delta b_{k}^{\text {old }}
\end{aligned}
$$

where $a_{k}^{\text {new }}, a_{k}^{\text {old }}, b_{k}^{\text {new }}$, and $b_{k}^{\text {old }}$ are the expansion factor and translation factor before and after adjustment, respectively. $\Delta a_{k}^{\text {old }}$ and $\Delta b_{k}^{\text {old }}$ are the momentum terms of the retractable factor and the translational factor, respectively. $\eta$ and $\lambda$ are learning rate and momentum factors, respectively, and their values range from 0 to $1 . \delta_{a_{k}}$ are $\delta_{b_{k}}$ derivatives function. 


\subsubsection{The Coupling Coordination Degree Model of PLEU}

The benign development of new-type urbanization requires the dynamic change of coupling and coordination among internal subsystems. Based on the results of WNN, the Coupling Coordination Degree model is used to analyze the coupling coordination relationship among PLEU. The specific model [54] is as follows:

$$
\begin{gathered}
T_{i}=\sum_{i=1}^{n} \omega_{i} A_{i} \\
C_{i}=n\left(\frac{\prod_{i=1}^{n} A_{i}}{\sum_{i=1}^{n} A_{i}}\right)^{\frac{1}{n}} \\
D_{i}=\left(C_{i} \times T_{i}\right)^{\frac{1}{2}}
\end{gathered}
$$

where $A_{i}(i=1,2, \ldots, n)$ is the evaluation value of each subsystem and $T_{i}$ is the comprehensive indicator of the new-type urbanization level. $\omega_{i}$ is the undetermined weight (entropy weight method is used to calculate the weight of (PLEU)). $C_{i}$ is a quantitative indicator to measure the degree of coupling and linkage between subsystems and $C_{i} \in(0,1)$. $D_{i}$ is the indicator that comprehensively measures the coupling and coordination relationship among subsystems, which has high stability and reflects the development process of new-type urbanization from disorder to order. Based on relevant studies [34,35], $D_{i}$ is divided into antagonistic disorder $\left(0 \leq D_{i}<0.1\right)$, moderate disorder $\left(0.1 \leq D_{i}<0.3\right)$, low disorder $\left(0.3 \leq D_{i}<0.5\right)$, general coordination $\left(0.5 \leq D_{i}<0.7\right)$, moderate coordination $\left(0.7 \leq D_{i}<0.9\right)$, and system optimization stage $\left(0.9 \leq D_{i} \leq 1\right)$.

\subsubsection{The Econometric Model for Analyzing the Impact of PLEU on Carbon Emissions}

Based on theoretical analysis and assumption, the econometric model was constructed, and the interference of other variables was controlled to empirically verify the influence mechanism of the coupling coordination relationship of the PLEU system on urban carbon emissions. The specific model [55] is as follows:

$$
C_{i t}=c+\beta_{1} D_{i t}+\beta_{2} D_{i t}^{2}+\sum_{n=1}^{m} \alpha_{n} X_{i t}^{n}+\varepsilon_{i t}
$$

where $C_{i t}$ is the explained variable, representing the total $\mathrm{CO}_{2}$ emissions of the ith city in the $t$ year. $\beta_{i}$ and $\alpha_{n}$ are the estimated parameters of explanatory variables and control variables, respectively. $D_{i t}$ is the explanatory variable, which is the PLEU coupling coordination degree of the $i$ th city in the $t$ year. Moreover, referring to relevant studies $[55,56]$, Per Capita GDP(PGDP), Urban Population Density (UPD), Per Capital Expenditure of Urban Households (PEUH), Total Import and Export Volume (TIEV), and Energy Consumption Added of Industrial (ECAI) were selected as control variables to obtain unbiased estimation.

\subsection{Data Resource and Handling}

The data employed in this paper include socioeconomic development and land usage of 17 cities in Shandong Province from 2007 to 2016. Socioeconomic data are obtained from the China Urban Statistics Yearbook, China Regional Economic Statistics Yearbook, and Shandong Statistical Yearbook, while land usage is retrieved mainly from the Land Survey Results Sharing Application Service Platform of the Ministry of Natural Resources of PRC [57]. Urban carbon emissions are calculated using coal consumption and gross industrial energy consumption statistics from the China Energy Statistic Yearbook [58]. Compared to other data sources, $\mathrm{CO}_{2}$ emissions at the municipal level can be obtained conveniently and accurately by this option [59]. Taking 2007 as the base year, the Consumer Price Index (CPI) was applied to deflate the price of nominal variables, such as Per Capita 
GDP, Investment in Fixed Assets, and Disposable Income. Additionally, all other variables except the coupling coordination degree of PLEU and Energy Consumption Added of Industrial (ECAI) are logarithmically handled in the econometric model to narrow the absolute value of variables and eliminate heteroscedasticity between variables as much as possible.

Based on WNN, the level of PLEU in 17 cities of Shandong from 2007 to 2016 was estimated by the applied MATLAB platform (Table A1, Table A2, Table A3). Meanwhile, ArcGIS 10.2 software was employed to spatially visualize the evaluation results to analyze the spatio-temporal evolution characteristics of PLEU. By the results of WNN, the weights of PLEU were determined objectively based on the Entropy Weighting Method [33] as $0.2642,0.4214$, and 0.3144 , respectively. Then, the coupling coordination relationship of PLEU in 17 cities was measured by adopting the Coupling Coordination Degree model (Table A4). Meanwhile, ArcGIS 10.2 software was applied to spatially visualize results to analyze spatio-temporal evolution characteristics of the coupling coordination relationship of PLEU.

The samples in the econometric model are short panel data. Typically, the Hausman Test was applied to determine whether a fixed or random effect should be used for regression. Before proceeding, the collinearity and heteroscedasticity of panel data must be examined. For conducting a Pooled Regression model, Stata 15.0 software was utilized, and the Variance Inflation Factor (VIF) was calculated. VIF of each variable is between 1 and 10, indicating that no multicollinearity occurred. To ensure the validity of model estimation results, the ADF Test was applied to verify the existence of the unit root. There was no unit root and all of the variables were first-order integration sequences, according to the results. The Kao Test was applied to validate panel data co-integration and the results show that variables and explanatory variables have a long-term, stable, co-integration relationship. Meanwhile, the $p$-value of the Hausman Test rejects random effects at the $1 \%$ significance level. Finally, the clustering robust standard error was applied to correct the regression results to eliminate the effect of heteroscedasticity and minimize the interference of random items.

\section{Results}

\subsection{Spatio-Temporal Characteristics of PLEU}

In respect of population urbanization, Shandong was in the preliminary development stage in 2007, with population agglomeration effects yet to be apparent in the majority of cities and only Qingdao, Jinan and Weihai had higher population urbanization (Figure 3). In contrast, all 17 cities of Shandong had reached a rapidly developing stage of population urbanization in 2016, with obvious intra-city population agglomeration effects and a gradually widening gap between cities. Spatially, regions with a higher level of population urbanization display evolutionary characteristics of spreading outward from Qingdao, Jinan, and Weihai. Population urbanization of cities in the eastern peninsula was always higher than that in the western and southern regions of Shandong. In respect to land urbanization, the level of land urbanization in Shandong was, overall, low in 2007, with the majority of cities being below 0.27 , and serious polarization existed. However, the overall level of land urbanization increased dramatically in 2016, with annual increases of more than $100 \%$ in all cities. Spatially, high-value areas of land urbanization present spatial characteristics of spreading from chaotic and disorderly fragmented distribution to surrounding cities and forming concentrated contiguous areas, with only Binzhou and Heze having the lower level of land urbanization in 2016. In respect to economic urbanization, Shandong is consistently higher. By 2016, the level of economic urbanization had exceeded 0.57 in all 17 cities, although average annual growth rates were relatively lower than population and land urbanization. Spatially, economic urbanization is more harmonized at interregional and smaller gaps exist between high-value and low-value areas. Simultaneously, high-value areas of economic urbanization tended to spread from the eastern peninsula to the central and western areas of Shandong, which is mainly 
attributed to the relatively reasonable industrial structure and layout as well as developed transportation networks in Shandong.

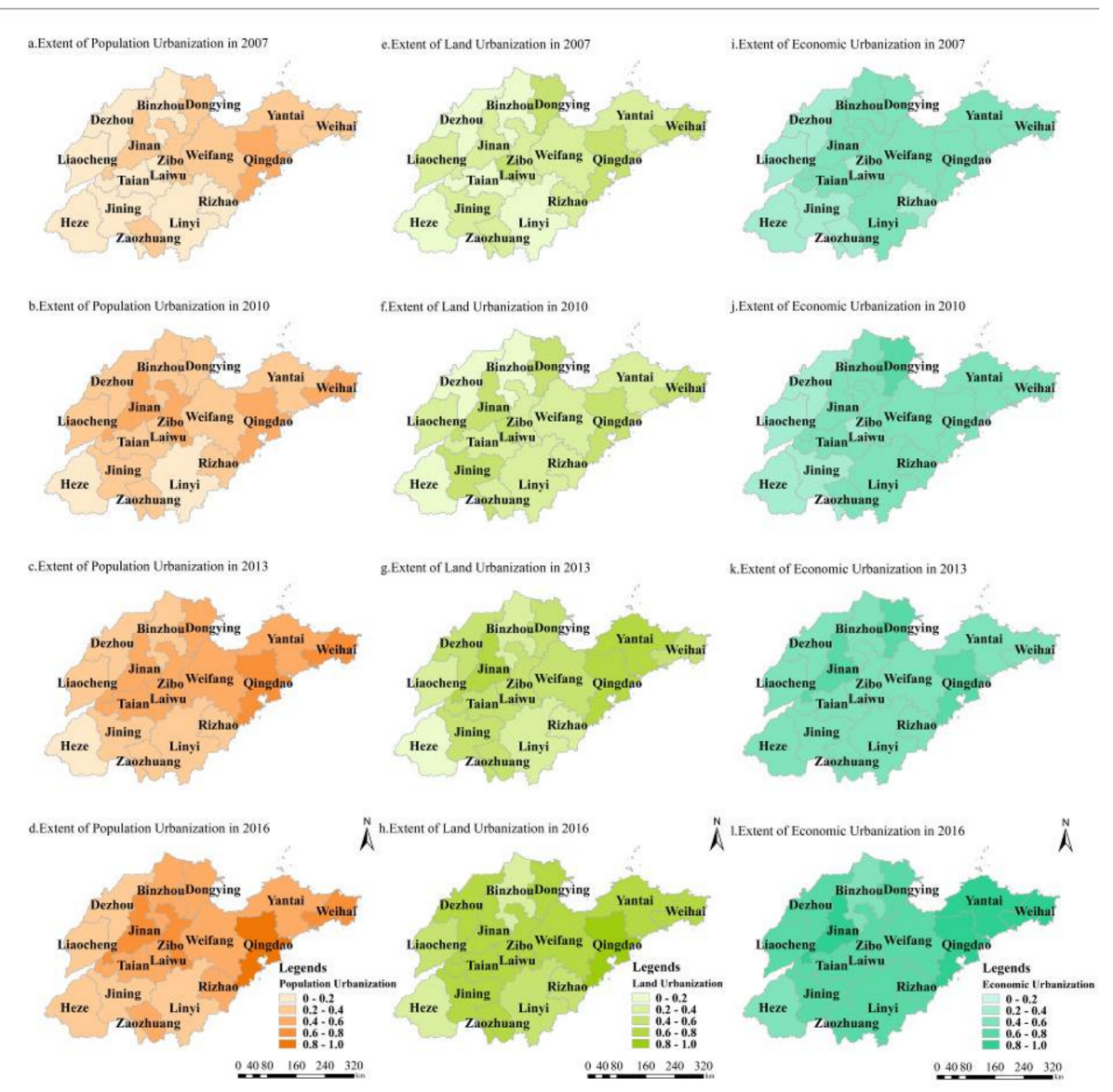

Figure 3. Spatio-temporal characteristics of population-land-economic urbanization (PLEU).

\subsection{Spatio-Temporal Characteristics of PLEU Coupling Coordination Degree}

Figure 4 depicts the dynamic evolution of the coupling coordination relationship of PLEU in Shandong from 2007 to 2016. In general, the coupling coordination relationship of PLEU in Shandong as a whole improved from moderate disorder in 2007 to moderate coordination in 2016, with more than a 300\% increase. Correspondingly, the coupling coordination degree of 17 cities grew rapidly and all had resolved the antagonistic disorder issue by 2016. The coupling coordination degree of PLEU in Qingdao was the first to advance to the stage of system optimization in 2011 and gradually spread to Jinan and Yantai. Meanwhile, except for Heze, all other 16 cities got rid of moderate disorder of the coupling coordination development of PLEU and realized the benign circulation of sustainable development of new-type urbanization. Furthermore, 17 cities had a higher average annual growth rate of the coupling coordination degree, among which, the average annual growth rate of all 16 cities exceeded 10\%, except Qingdao, and exceeded 26\% in 7 cities, including Taian and Liaocheng. Despite the lower coupling coordination degree of Heze, the average annual growth rate reaches more than $37 \%$. Spatially, the average annual growth rate demonstrates the tendency of gradually decreasing from western inland cities to eastern peninsula cities, and significant polarization exists. Overall, the coupling coordination relationship of PLEU had greatly improved in 17 cities of Shandong from 2007 to 2016, in which 12 cities reached general coordination or above, but Heze, Binzhou, Liaocheng, Rizhao, and Linyi continued to suffer from the issue of low disorder. There has always been a phenomenon that economic urbanization is higher than land urbanization and land urbanization is higher than population urbanization in these cities, and rapidly expanding urban construction land lacks sufficient population support. 


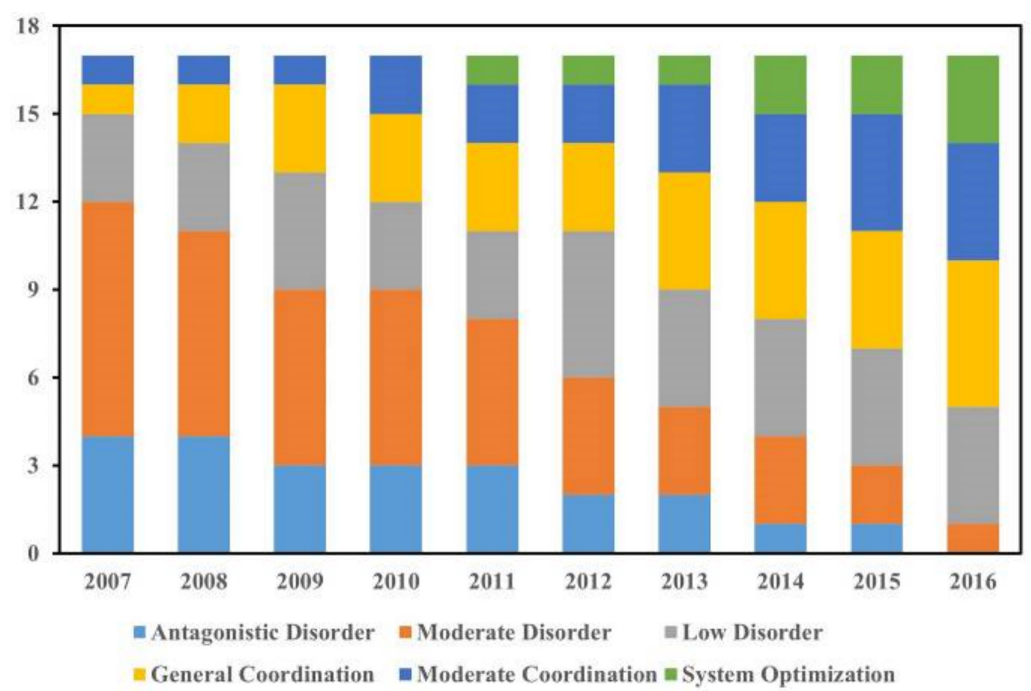

Figure 4. Stacking diagram of coupling coordination relation.

From the perspective of spatiality (Figure 5), the regional discrepancy in the coupling coordination relationship of PLEU among 17 cities of Shandong from 2007 to 2016 is relatively minor. However, the clustering characteristics of Qingdao and Jinan as the core, respectively, are still observed, as well as the coupling coordination degree that diminishes from Qingdao and Jinan as the core to the periphery. The coupling coordination relationship between the two cities is significantly improved by the integrated influence of Qingdao and Jinan in the region, and eastern peninsula cities were always superior to that of central and western areas. The analysis concluded that Qingdao and Jinan consistently had the highest level of economic urbanization in Shandong from 2007 to 2016, with well-developed transportation networks, obvious location advantages, and relatively reasonable industrial structures and layouts. In particular, both cities are sub-provincial cities that receive major support from the central government in terms of policies and finances, which have significant siphoning effects on other cities in Shandong. Additionally, on the one hand, more reasonable urban planning and land use planning have contributed to the expansion of urban construction land in both cities and to ensure outward urban development. On the other hand, local governments have also focused on urban sustainability and realized connotative urban development by exploiting urban land-use potential. Accompanied by a continuously improving urbanization level, the spatial spillover effect has prompted the diversification of interregional population clustering and equalization of resource element allocation, which eventually brought about the improvement of the coupling coordination relationship among neighboring cities. However, cities including Heze, Liaocheng, Dezhou, and Zaozhuang are located in western Shandong and have lagged behind in economic development compared with other cities. Meanwhile, as typical resources-oriented cities, they have a single industrial structure that makes it difficult to support the sustainable development of PLEU. It is difficult to provide enough jobs because of the single industrial structure, but local governments are eager to expand land. Resource endowment, geographical location, socioeconomic development, industrial structure layout, government policies, and other factors caused the development of PLEU disorder in these cities. 


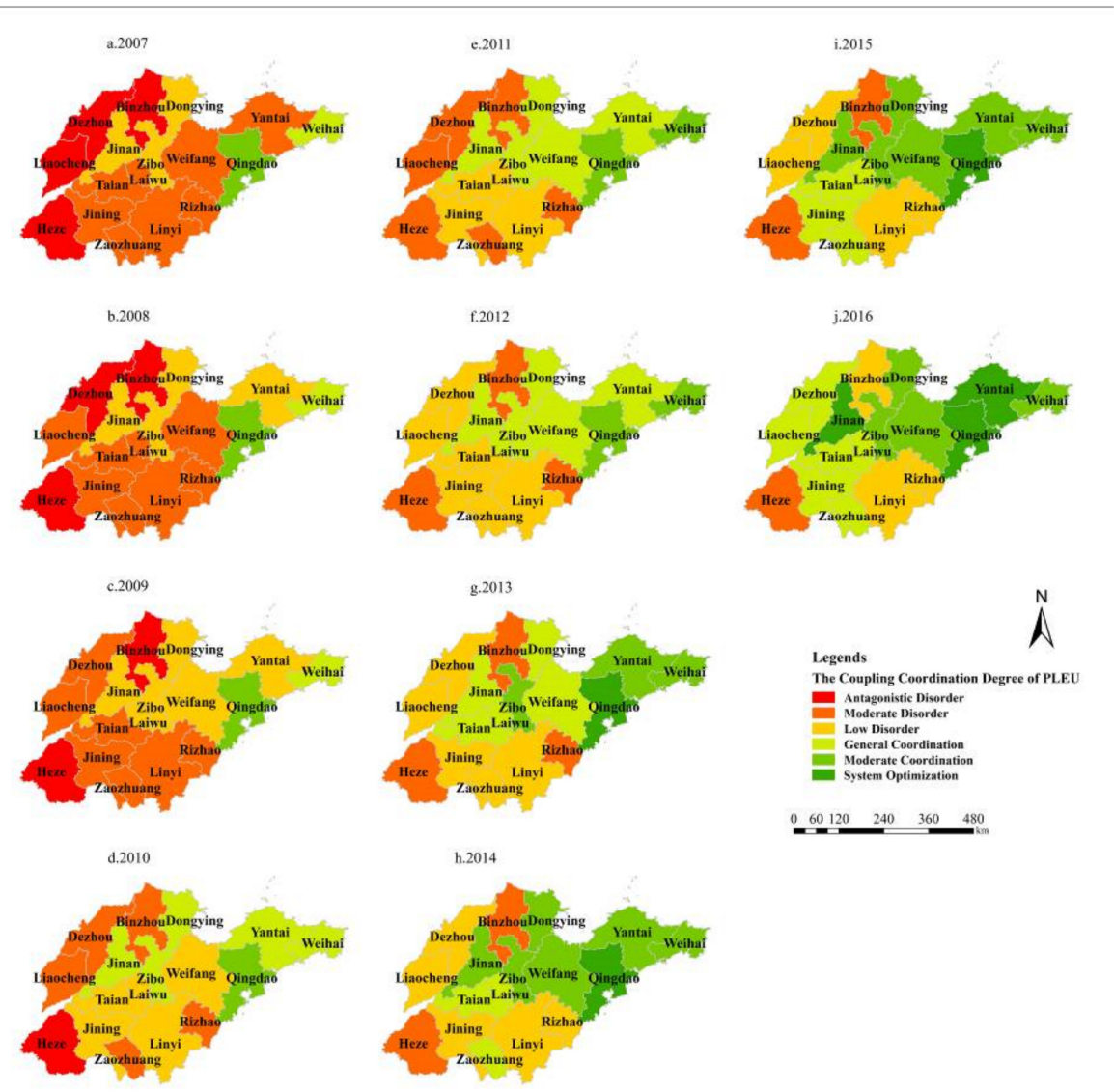

Figure 5. Spatio-temporal characteristics of coupling coordination relationship of PLEU.

\subsection{Econometric Analysis of PIEU's Impact on Carbon Emissions}

The parameter estimation directly adopted the coupling coordination degree of PLEU, higher values indicate that PLEU is in more coordinated, interrelated, and interactive relationships. Table 2 summarizes the descriptive statistics of each variable, and parameter estimation results of fixed and random effects. The R2-value exceeds $75 \%$, which indicates that the regression results are reasonably reliable. Whether fixed effects or random effects, the coupling coordination degree of PLEU has significant positive effects on urban $\mathrm{CO}_{2}$ emissions when other factors are controlled, whereas the squared value of the coupling coordination degree of PLEU has significant negative effects on urban $\mathrm{CO}_{2}$ emissions. The influence of the coupling coordination degree of PLEU on urban $\mathrm{CO}_{2}$ emissions exhibits an inverted, U-shaped characteristic, with an inflection point of change is 0.6374 (based on the fixed-effect regression measurement), which indicated that with the improvement of the coupling coordination degree of PLEU and exceeding 0.6374 , urban $\mathrm{CO}_{2}$ emissions display the trend of first increasing and then decreasing, confirming our hypothesis. The analysis holds that what makes new-type urbanization distinguishable from traditional urbanization patterns depends on more coordination of the interactions among population, land, economy, and other subsystems, enhancing the efficiency of resource utilization, modifying previous rudimentary development paths, and dramatically minimizing the impact on the environment. Simultaneously, the coupling and coordination of various subsystems of new-type urbanization is a dynamic evolutionary process, which requires a balance between urban development and environmental ecology to reach the coupling coordination relationship of system-optimized PLEU. During this process, the optimization of element input and resource allocation will inevitably be required to improve the coupling coordination relationship of PLEU, which will lead to an inverted, U-shaped change characteristic of urban carbon emissions that grows first and then drop. 
Table 2. Descriptive statistical analysis and regression results.

\begin{tabular}{|c|c|c|c|c|c|c|c|}
\hline Variable & Units & Mean & $\begin{array}{l}\text { Standard } \\
\text { Error }\end{array}$ & Minimum & Maximum & $\mathrm{FE}$ & RE \\
\hline ln Total $\mathrm{CO}_{2}$ Emissions & $\begin{array}{l}\text { Millions of } \\
\text { tons }\end{array}$ & 3.613 & 0.574 & 1.692 & 4.370 & & \\
\hline $\begin{array}{l}\text { PLEU Coupling } \\
\text { Coordination Degree }\end{array}$ & & 0.455 & 0.246 & 0.007 & 0.955 & $\begin{array}{l}0.385^{*} \\
(2.71)\end{array}$ & $\begin{array}{l}0.361 * \\
(2.51)\end{array}$ \\
\hline $\begin{array}{l}\text { Squared of PLEU Coupling } \\
\text { Coordination Degree }\end{array}$ & & 0.267 & 0.244 & 0.00004 & 0.913 & $\begin{array}{l}-0.302 * * \\
(-3.59)\end{array}$ & $\begin{array}{l}-0.287^{* * *} \\
(-3.38)\end{array}$ \\
\hline In Per Capita GDP & yuan & 10.996 & 0.578 & 9.124 & 12.379 & $\begin{array}{l}0.008 \\
(0.22)\end{array}$ & $\begin{array}{l}0.007 \\
(0.21)\end{array}$ \\
\hline In Urban Population Density & Person $/ \mathrm{km}^{2}$ & 9.312 & 0.391 & 8.411 & 10.151 & $\begin{array}{l}0.0006 \\
(0.03)\end{array}$ & $\begin{array}{l}-0.001 \\
(-0.07)\end{array}$ \\
\hline $\begin{array}{c}\text { In Per Capital Expenditure of } \\
\text { Urban Households }\end{array}$ & yuan & 9.609 & 0.291 & 8.826 & 10.259 & $\begin{array}{l}0.152 * \\
(2.91)\end{array}$ & $\begin{array}{l}0.147^{* *} \\
(2.83)\end{array}$ \\
\hline $\begin{array}{l}\text { In Total Import and } \\
\text { Export Volume }\end{array}$ & yuan & 15.259 & 1.120 & 12.915 & 17.709 & $\begin{array}{l}0.044^{* *} \\
(3.36)\end{array}$ & $\begin{array}{l}0.049^{* * *} \\
(3.43)\end{array}$ \\
\hline $\begin{array}{c}\text { Energy Consumption Added } \\
\text { of Industrial }\end{array}$ & $\%$ & 1.707 & 0.912 & 0.575 & 6.110 & $\begin{array}{l}0.038 \\
(1.24)\end{array}$ & $\begin{array}{l}0.031 \\
(1.00)\end{array}$ \\
\hline Constant & & & & & & $\begin{array}{l}1.278 * \\
(2.54)\end{array}$ & $\begin{array}{l}1.287^{*} \\
(2.32)\end{array}$ \\
\hline Observations & & 170 & 170 & 170 & 170 & 170 & 170 \\
\hline Adjusted $\mathrm{R}^{2}$ & & & & & & 0.7399 & 0.7396 \\
\hline Hausman test & & & & & & Accept & Reject \\
\hline
\end{tabular}

Notes: Figures in parentheses denote the standard errors of the respective coefficients, while ${ }^{* * *} / * *{ }^{*}$ indicate significance at the $1 \% / 5 \% / 10 \%$ levels, respectively.

In addition, with respect to control variables, Per Capital Expenditure of Urban Households and Total Import and Export Volume both show significant driving effects on Urban $\mathrm{CO}_{2}$ Emissions. Correspondingly, Per Capita GDP, Urban Population Density, and Energy Consumption Added to Industrial have no significant impact on Urban $\mathrm{CO}_{2}$ Emissions. The analysis argues that household consumption expenditures can facilitate household energy consumption and household living carbon consumption has become an important part of global carbon emissions and has become a new growth driver [60]. Contemporaneously, as one of the more economically developed regions in China, Shandong has advantages in a variety of industries and industrialization, and plays an integral role in globalization trade, which will inevitably contribute to the increase of urban carbon emissions while undertaking more international trade shares. Population density indicates land carrying capacity and the insignificance of regression results may be explained by the more reasonable distribution of the population in Shandong, which has no discernible effect on urban carbon emissions. Similarly, the insignificant effect of Per Capita GDP on urban carbon emissions indicates the regional differences of more reasonable economic growth in Shandong. The results for Energy Consumption Added to Industrial seem to defy common sense, possibly because the ongoing industrial upgrading and energy restructuring policy in Shandong has reduced energy consumption, but the inertia of economic development has led to the policy that remains to be tested over time.

\section{Discussions}

Practical experience has shown that social ecosystems and natural ecosystems are never antagonistic, but rather interactive and symbiotic [61]. The Chinese government has not only proposed the new-type urbanization strategy to achieve harmonious coexistence between humans and nature but has also provided a series of policy measures to promote sustainable urban development. Examples include the low-carbon eco-city construction promoted at the city scale, such as the Sino-Singapore Tianjin Eco-city and Tangshan Bay Eco-city [62], the sponge city policy that started in 2014 [63], and the advocacy of green buildings and green infrastructure at the neighborhood scale. Meanwhile, rapid urban 
land expansion has also prompted the Chinese government to pay long-term attention to environmental degradation caused by changes in soil carbon stock. Policies, such as clay soil protection [64], the linkage between urban and rural construction land increase and decrease, and land reclamation have been implemented to improve the soil environment and maintain the amount of arable land. In addition, attempts have been made to break the urban-rural dual system and to guide more rural laborers to move freely between urban-rural areas. A series of measures dedicated to the equalization of public services will also improve social conflicts and eliminate inequalities.

Given that urbanization is a compulsory period for low-income countries to reach middle-income countries, promotion of organic coordination among various subsystems and minimizing environmental costs should be the focus of government policymakers and academic researchers. Currently, the global environment is confronted with major obstacles to sustainable development challenges and the new-type urbanization strategy of China has provided an effective alternative for other emerging countries worldwide. Balancing economic growth with environmental conservation can be accomplished in the following manner, based on China's development experience. To begin, appropriate measures could be planned and designed at the highest strategic levels to address sustainable development concerns and establish scientific development goals. For example, in China, new-type urbanization strategies emphasize the harmonious cohabitation of people and nature as a primary growth goal. Second, policymakers should discard the traditional economic growth pattern as the criterion for evaluation, align new-type urbanization with national conditions, and embrace more integrated, open, inclusive, coordinated, and sustainable development paradigms. Finally, a variety of engineering and technical methods, such as green infrastructure, ecological corridors, and nature-based solutions could be used to restore and improve ecosystems, as well as to construct green cities and sponge cities [63].

Although this paper focuses on the impacts of new-type urbanization strategies on sustainable urban development, some shortcomings still exist. The social structure and lifestyle changes triggered by urban-rural migration will not only change the energy consumption structure at the micro level, but also cause a dramatic transformation of the urban-rural environment at the macro level [65]. Meanwhile, abundant established studies have confirmed that urban economic growth has a significant impact on carbon emissions [66]. Last but not least, the transformation from agricultural land to urban land would also cause dramatic changes in the soil carbon stock [67]. In short, changes in population, land, and the economy would all contribute to changes in urban carbon emissions and analysis of the aspect is not adequately considered in this paper. The main reason is that this paper is concerned with the impact of the interaction between population-land-economy as the subsystems of new-type urbanization on sustainable urban development. However, this does not mean that this paper is meaningless. Based on theoretical analysis and empirical verification, it is found that economic urbanization is much faster than land urbanization and land urbanization is much faster than population urbanization in Shandong. Also, under the comprehensive influence of population, land, and the economy, urban carbon emissions demonstrate the characteristics of changes that first increase and then decrease. This indicates that the traditional urbanization path of focusing only on one aspect should not be continued and the implementation of new-type urbanization should be considered comprehensively from a systemic perspective.

\section{Conclusions}

The transformation from traditional urbanization to new-type urbanization reflects the Chinese government's determination to improve the environment, promote sustainable development, and achieve the goals of carbon peaking and carbon neutrality [68]. Humanoriented new-type urbanization involves multidimensional complex systems of population, land, and the economy, the benign development of which is contingent on the coupling coordinated interactions among subsystems. This paper explores the interaction and interrelated relationship of PLEU and its impact mechanism on urban carbon emissions. A 
total of 17 cities of Shandong Province were taken as the study area. First, the level of PLEU from 2007 to 2016 was measured by WNN, and the coupling coordination relationship of PLEU was measured using the Coupling Coordination Degree Model. Second, ArcGIS 10.2 software was applied to spatially visualize results. Finally, the econometric model was established to analyze the effect of coupling coordination degree of PLEU on urban carbon emissions.

There are three key findings in this paper. First, the level of PLEU in Shandong dramatically increased in all cities from 2007 to 2016. 17 cities have obvious population agglomeration effects, a large amount of surplus rural labor flowed to cities and the growth of population magnitude increased the demand for urban construction land. By expanding land to the periphery and tapping internal land potential, the degree of land urbanization in most cities has subsequently increased. With land urbanization as a carrier and population urbanization as the core, economic urbanization has developed rapidly. However, the disparity of urban economic development has tended to widen further due to some factors, such as city scales and administrative levels. In China, high administrative level cities tend to receive more policy support, have more developed economies, and are able to attract more immigrants.

Second, from 2007 to 2016, 17 cities in Shandong have gotten rid of the antagonism disorder. However, cities, including Heze, Liaocheng, Dezhou, and Zaozhuang are located in western Shandong and have lagged in economic development compared with other cities. Meanwhile, as typical resources-oriented cities, they have a single industrial structure, which makes it difficult to support the sustainable development of PLEU. From a spatial perspective, the coupling coordination degree of PLEU showed that the agglomeration characteristics with Qingdao and Jinan as cores, respectively, and the coupling coordination degree spreads to the periphery with Qingdao and Jinan as cores, and decreases. Qingdao and Jinan, as the two largest cities in Shandong, had been listed as two central cities in the Shandong Peninsula City Cluster. The government hopes to radiate and drive other cities in the region by enhancing Qingdao and Jinan's element concentration, industrial attraction, and economic engine capacity, forming an organic and coordinated element circulation network, industrial complementary mechanism, and city system.

Third, the influence of the coupling coordination degree of PLEU on urban carbon emissions presents an inverted, U-shape characteristic in Shandong, which indicates that the total urban carbon emissions will initially increase and subsequently decline as the coupling coordination relationship improves. The enhancement of coupling coordination of PLEU requires the mobilization of the population, land, capital, and other elements and optimization of resource allocation utilizing reform and innovation. The coupling coordination relationship of PLEU will be optimized in the trade-off between urban development and environmental development, with the cost of increasing urban carbon emissions, but this increase will be controlled in a better coupling coordination relationship of PLEU. In addition, Per Capital Expenditure of Urban Households, as well as Total Import and Export Volume both show significant driving effects on urban $\mathrm{CO}_{2}$ emissions.

PLEU is a complex system composed of numerous elements and contains numerous subsystems, which is the dynamic process wherein non-urban construction land is transformed into urban construction land, the population is concentrated in cities, industries are concentrated, and element resources are optimally allocated. The coupling coordinated development of PLEU is not only used to realize the aggregation of urban elements and economic growth but also pays attention to the organic integration of social ecosystem and natural ecosystems. The coupling coordination degree of PLEU is affected by industrial structure layout, resource endowment, macroeconomic policy, and other factors, and thus the impact of different coupling coordination relationships on regional integrated development and sustainable environmental use is urgently in need of theoretical and empirical studies at broader scales and dimensions. 
Author Contributions: Conceptualization: K.L. and J.W.; methodology: K.L. and X.K.; software: X.K. and J.L.; validation: Z.X. and K.D.; formal analysis: K.L.; investigation: J.W.; resources: X.K.; data curation: K.L.; writing-original draft preparation: K.L. and X.Z.; writing-review and editing: X.K. and Z.X.; visualization: K.L. and Z.X.; supervision: J.W. and K.D.; project administration, K.L. and K.D.; funding acquisition: J.W. All authors have read and agreed to the published version of the manuscript.

Funding: This work was funded by the National Social Science Foundation of China (Grant No. 18CJL041).

Data Availability Statement: The data presented in this study are available on request from the corresponding author.

Acknowledgments: We would like to express our appreciation to the anonymous reviewers for the insightful comments that improved this manuscript.

Conflicts of Interest: The authors declare no conflict of interest.

\section{Appendix A}

Table A1. Population urbanization level of Shandong from 2007 to 2016.

\begin{tabular}{|c|c|c|c|c|c|c|c|c|c|c|}
\hline City & 2007 & 2008 & 2009 & 2010 & 2011 & 2012 & 2013 & 2014 & 2015 & 2016 \\
\hline Jinan & 0.3422 & 0.3987 & 0.3827 & 0.4239 & 0.4935 & 0.4839 & 0.5261 & 0.6684 & 0.7175 & 0.7765 \\
\hline Qingdao & 0.4471 & 0.4489 & 0.4990 & 0.5274 & 0.5659 & 0.6288 & 0.6699 & 0.7212 & 0.7729 & 0.8528 \\
\hline Zibo & 0.3145 & 0.3849 & 0.4105 & 0.5006 & 0.5308 & 0.5478 & 0.5279 & 0.5892 & 0.6050 & 0.6592 \\
\hline Zaozhuang & 0.2066 & 0.2388 & 0.2752 & 0.3218 & 0.3475 & 0.3772 & 0.3887 & 0.4092 & 0.4396 & 0.4112 \\
\hline Dongying & 0.3076 & 0.3073 & 0.3224 & 0.3165 & 0.3649 & 0.3602 & 0.4525 & 0.4932 & 0.5076 & 0.5113 \\
\hline Yantai & 0.2936 & 0.3205 & 0.3321 & 0.3698 & 0.4068 & 0.4681 & 0.5370 & 0.5501 & 0.5584 & 0.5702 \\
\hline Weifang & 0.2303 & 0.2679 & 0.3027 & 0.3670 & 0.3900 & 0.4011 & 0.4164 & 0.4433 & 0.4616 & 0.4706 \\
\hline Jining & 0.1026 & 0.1255 & 0.1769 & 0.2004 & 0.2106 & 0.2500 & 0.2988 & 0.3543 & 0.3693 & 0.3951 \\
\hline Taian & 0.1420 & 0.1838 & 0.2678 & 0.3693 & 0.3503 & 0.3474 & 0.4238 & 0.4508 & 0.4466 & 0.4483 \\
\hline Weihai & 0.3581 & 0.4768 & 0.5088 & 0.5627 & 0.5970 & 0.6346 & 0.6534 & 0.6872 & 0.6815 & 0.7052 \\
\hline Rizhao & 0.1763 & 0.1903 & 0.2034 & 0.2123 & 0.2580 & 0.2896 & 0.2904 & 0.3216 & 0.3430 & 0.4039 \\
\hline Laiwu & 0.1845 & 0.2350 & 0.2711 & 0.3044 & 0.3167 & 0.3615 & 0.4267 & 0.4452 & 0.4687 & 0.4758 \\
\hline Linyi & 0.0677 & 0.1191 & 0.1497 & 0.1723 & 0.1644 & 0.2080 & 0.2540 & 0.2855 & 0.3158 & 0.3683 \\
\hline Dezhou & 0.1054 & 0.1794 & 0.2075 & 0.2554 & 0.2815 & 0.3249 & 0.3324 & 0.3756 & 0.3768 & 0.3905 \\
\hline Liaocheng & 0.1129 & 0.1527 & 0.1867 & 0.2003 & 0.2560 & 0.2748 & 0.2820 & 0.2886 & 0.3048 & 0.3176 \\
\hline Binzhou & 0.1946 & 0.2278 & 0.2618 & 0.2965 & 0.3129 & 0.3727 & 0.3783 & 0.4159 & 0.4315 & 0.4844 \\
\hline Heze & 0.0445 & 0.0624 & 0.0943 & 0.1348 & 0.1738 & 0.1898 & 0.1970 & 0.2053 & 0.2369 & 0.2367 \\
\hline Mean & 0.2136 & 0.2541 & 0.2854 & 0.3256 & 0.3542 & 0.3836 & 0.4150 & 0.4532 & 0.4728 & 0.4987 \\
\hline
\end{tabular}


Table A2. Land urbanization level of Shandong from 2007 to 2016.

\begin{tabular}{|c|c|c|c|c|c|c|c|c|c|c|}
\hline City & 2007 & 2008 & 2009 & 2010 & 2011 & 2012 & 2013 & 2014 & 2015 & 2016 \\
\hline Jinan & 0.3988 & 0.4011 & 0.4278 & 0.4737 & 0.5262 & 0.5865 & 0.6430 & 0.7037 & 0.7629 & 0.7923 \\
\hline Qingdao & 0.4526 & 0.4494 & 0.4818 & 0.5407 & 0.6086 & 0.6495 & 0.7105 & 0.7605 & 0.8096 & 0.8823 \\
\hline Zibo & 0.2980 & 0.3191 & 0.3380 & 0.3780 & 0.4789 & 0.5189 & 0.5653 & 0.6060 & 0.6328 & 0.7358 \\
\hline Zaozhuang & 0.2432 & 0.2449 & 0.2526 & 0.2946 & 0.3547 & 0.3771 & 0.4514 & 0.5342 & 0.5902 & 0.6782 \\
\hline Dongying & 0.4025 & 0.4231 & 0.4427 & 0.4860 & 0.4889 & 0.4767 & 0.5299 & 0.5647 & 0.5936 & 0.6385 \\
\hline Yantai & 0.2685 & 0.3006 & 0.3366 & 0.3851 & 0.4315 & 0.5846 & 0.6588 & 0.6649 & 0.6525 & 0.7032 \\
\hline Weifang & 0.2240 & 0.2420 & 0.3252 & 0.3884 & 0.4317 & 0.4618 & 0.4914 & 0.5245 & 0.5923 & 0.6732 \\
\hline Jining & 0.3550 & 0.3722 & 0.3980 & 0.4364 & 0.4723 & 0.5096 & 0.5280 & 0.5612 & 0.5765 & 0.6694 \\
\hline Taian & 0.1855 & 0.2355 & 0.2184 & 0.2844 & 0.3113 & 0.3750 & 0.4578 & 0.5836 & 0.6096 & 0.6546 \\
\hline Weihai & 0.4447 & 0.4456 & 0.4699 & 0.4920 & 0.4846 & 0.5061 & 0.5179 & 0.5483 & 0.6042 & 0.7740 \\
\hline Rizhao & 0.2627 & 0.2712 & 0.2715 & 0.2729 & 0.2975 & 0.3264 & 0.3574 & 0.4049 & 0.4356 & 0.4661 \\
\hline Laiwu & 0.4315 & 0.4452 & 0.4679 & 0.4586 & 0.4853 & 0.5016 & 0.5128 & 0.5740 & 0.6388 & 0.6643 \\
\hline Linyi & 0.1522 & 0.1571 & 0.1984 & 0.2399 & 0.2563 & 0.2925 & 0.3598 & 0.4268 & 0.4597 & 0.4425 \\
\hline Dezhou & 0.1663 & 0.1331 & 0.1527 & 0.1868 & 0.2510 & 0.3708 & 0.4001 & 0.4940 & 0.5126 & 0.6256 \\
\hline Liaocheng & 0.2085 & 0.2374 & 0.2489 & 0.2726 & 0.2813 & 0.3495 & 0.3929 & 0.4721 & 0.4482 & 0.4675 \\
\hline Binzhou & 0.1172 & 0.1290 & 0.1774 & 0.1637 & 0.1769 & 0.2118 & 0.2631 & 0.3303 & 0.3442 & 0.3808 \\
\hline Heze & 0.0243 & 0.0572 & 0.0715 & 0.0960 & 0.1066 & 0.1111 & 0.1384 & 0.1774 & 0.1873 & 0.2302 \\
\hline Mean & 0.2727 & 0.2861 & 0.3105 & 0.3441 & 0.3790 & 0.4241 & 0.4693 & 0.5254 & 0.5559 & 0.6164 \\
\hline
\end{tabular}

Table A3. Economic urbanization level of Shandong from 2007 to 2016.

\begin{tabular}{|c|c|c|c|c|c|c|c|c|c|c|}
\hline City & 2007 & 2008 & 2009 & 2010 & 2011 & 2012 & 2013 & 2014 & 2015 & 2016 \\
\hline Jinan & 0.4847 & 0.4927 & 0.5003 & 0.5060 & 0.5416 & 0.5861 & 0.6174 & 0.6966 & 0.7639 & 0.8391 \\
\hline Qingdao & 0.5702 & 0.5521 & 0.5506 & 0.5610 & 0.5810 & 0.6214 & 0.7164 & 0.7713 & 0.8467 & 0.9067 \\
\hline Zibo & 0.4520 & 0.4590 & 0.4674 & 0.4725 & 0.4747 & 0.5103 & 0.5859 & 0.6901 & 0.6957 & 0.7574 \\
\hline Zaozhuang & 0.3912 & 0.3968 & 0.4058 & 0.4124 & 0.4323 & 0.4408 & 0.4274 & 0.4784 & 0.5446 & 0.6480 \\
\hline Dongying & 0.5340 & 0.5565 & 0.5749 & 0.6017 & 0.6280 & 0.6319 & 0.6753 & 0.6678 & 0.6962 & 0.7760 \\
\hline Yantai & 0.5096 & 0.4931 & 0.4998 & 0.5041 & 0.5114 & 0.5137 & 0.5546 & 0.6225 & 0.7523 & 0.8369 \\
\hline Weifang & 0.4139 & 0.4175 & 0.4274 & 0.4366 & 0.4443 & 0.4727 & 0.5845 & 0.6651 & 0.7442 & 0.7514 \\
\hline Jining & 0.3878 & 0.3929 & 0.3985 & 0.3932 & 0.4296 & 0.4391 & 0.4158 & 0.4870 & 0.5337 & 0.6609 \\
\hline Taian & 0.4063 & 0.4135 & 0.4263 & 0.4351 & 0.4475 & 0.4527 & 0.4665 & 0.5871 & 0.6662 & 0.7195 \\
\hline Weihai & 0.4952 & 0.4883 & 0.4871 & 0.4842 & 0.4833 & 0.5403 & 0.5933 & 0.6830 & 0.7490 & 0.8134 \\
\hline Rizhao & 0.3745 & 0.4168 & 0.3878 & 0.4491 & 0.4904 & 0.5619 & 0.5808 & 0.5960 & 0.6162 & 0.6970 \\
\hline Laiwu & 0.2467 & 0.2675 & 0.2829 & 0.3282 & 0.3748 & 0.4420 & 0.4802 & 0.5436 & 0.6305 & 0.6517 \\
\hline Linyi & 0.4071 & 0.4114 & 0.4150 & 0.4271 & 0.4386 & 0.4651 & 0.5477 & 0.6550 & 0.7578 & 0.7422 \\
\hline Dezhou & 0.3754 & 0.3945 & 0.3885 & 0.3940 & 0.4182 & 0.4723 & 0.4922 & 0.5512 & 0.6342 & 0.6703 \\
\hline Liaocheng & 0.3411 & 0.3482 & 0.3618 & 0.3734 & 0.4012 & 0.4715 & 0.5957 & 0.5945 & 0.6008 & 0.6439 \\
\hline Binzhou & 0.4269 & 0.4342 & 0.4365 & 0.4252 & 0.4527 & 0.4416 & 0.4357 & 0.4239 & 0.4801 & 0.5843 \\
\hline Heze & 0.2547 & 0.2882 & 0.3167 & 0.3328 & 0.3818 & 0.3990 & 0.4033 & 0.4130 & 0.4214 & 0.4279 \\
\hline Mean & 0.4160 & 0.4249 & 0.4310 & 0.4433 & 0.4666 & 0.4978 & 0.5396 & 0.5957 & 0.6549 & 0.7133 \\
\hline
\end{tabular}


Table A4. The coupling coordination indicator of PLEU in Shandong from 2007 to 2016.

\begin{tabular}{|c|c|c|c|c|c|c|c|c|c|c|}
\hline City & 2007 & 2008 & 2009 & 2010 & 2011 & 2012 & 2013 & 2014 & 2015 & 2016 \\
\hline Jinan & 0.3524 & 0.4018 & 0.4868 & 0.5197 & 0.5654 & 0.6243 & 0.6902 & 0.7458 & 0.8732 & 0.9221 \\
\hline Qingdao & 0.7225 & 0.7531 & 0.7929 & 0.8102 & 0.8487 & 0.8965 & 0.9135 & 0.9206 & 0.9385 & 0.9553 \\
\hline Zibo & 0.3276 & 0.4436 & 0.4935 & 0.5956 & 0.6461 & 0.6872 & 0.7242 & 0.7541 & 0.7893 & 0.8030 \\
\hline Zaozhuang & 0.1556 & 0.1767 & 0.2031 & 0.2217 & 0.2935 & 0.3417 & 0.4567 & 0.5286 & 0.5916 & 0.6588 \\
\hline Dongying & 0.3380 & 0.3868 & 0.4508 & 0.5972 & 0.6252 & 0.6480 & 0.6843 & 0.7262 & 0.7563 & 0.7846 \\
\hline Yantai & 0.2898 & 0.3744 & 0.4549 & 0.5275 & 0.5999 & 0.6726 & 0.7544 & 0.8290 & 0.8853 & 0.9130 \\
\hline Weifang & 0.2060 & 0.2815 & 0.3618 & 0.4542 & 0.5047 & 0.5693 & 0.6843 & 0.7244 & 0.8027 & 0.8778 \\
\hline Jining & 0.1699 & 0.1976 & 0.2465 & 0.3033 & 0.3579 & 0.4075 & 0.4508 & 0.4903 & 0.5398 & 0.5733 \\
\hline Taian & 0.1835 & 0.2140 & 0.2857 & 0.3112 & 0.4038 & 0.4637 & 0.5189 & 0.5974 & 0.6235 & 0.6627 \\
\hline Weihai & 0.5001 & 0.5781 & 0.6159 & 0.6753 & 0.7498 & 0.7638 & 0.7948 & 0.8415 & 0.8749 & 0.8999 \\
\hline Rizhao & 0.1276 & 0.1560 & 0.1703 & 0.1905 & 0.2267 & 0.2945 & 0.2670 & 0.3107 & 0.3585 & 0.4074 \\
\hline Laiwu & 0.2438 & 0.2915 & 0.3594 & 0.4257 & 0.4510 & 0.5045 & 0.5492 & 0.5479 & 0.5938 & 0.6189 \\
\hline Linyi & 0.1849 & 0.2413 & 0.2895 & 0.3583 & 0.3948 & 0.4188 & 0.4377 & 0.4670 & 0.4618 & 0.4892 \\
\hline Dezhou & 0.0730 & 0.0954 & 0.1091 & 0.1350 & 0.1841 & 0.3518 & 0.4694 & 0.4318 & 0.4821 & 0.5155 \\
\hline Liaocheng & 0.0781 & 0.1132 & 0.1703 & 0.2436 & 0.2698 & 0.3578 & 0.4079 & 0.4238 & 0.4815 & 0.5010 \\
\hline Binzhou & 0.0775 & 0.0853 & 0.0904 & 0.1102 & 0.1708 & 0.1987 & 0.2232 & 0.2363 & 0.2435 & 0.3326 \\
\hline Heze & 0.0067 & 0.0109 & 0.0244 & 0.0486 & 0.1095 & 0.1240 & 0.1308 & 0.1611 & 0.2413 & 0.2822 \\
\hline Mean & 0.1523 & 0.2071 & 0.2820 & 0.3684 & 0.4626 & 0.5092 & 0.5377 & 0.5887 & 0.6414 & 0.7032 \\
\hline
\end{tabular}

\section{References}

1. Liu, T.Y.; Su, C.W.; Jiang, X.Z. Is economic growth improving urbanisation? A cross-regional study of China. Urb. Stud. 2015, 52, 1883-1898. [CrossRef]

2. Han, H.; Li, H. Coupling coordination evaluation between population and land urbanization in Ha-Chang urban agglomeration. Sustainability 2020, 12, 357. [CrossRef]

3. United Nations, Department of Economic and Social Affairs, Population Division. World Urbanization Prospects (The 2014 Revision); UN: New York, NY, USA, 2014; pp. 7-36.

4. Pu, Y.R.; Wang, Y.Y.; Wang, P. Driving effects of urbanization on city-level carbon dioxide emissions: From multiple perspectives of urbanization. Int. J. Urb. Sci. 2022, 26, 108-128. [CrossRef]

5. Luo, Y.; Shen, J.; Chen, A.; Tao, Q.; Li, Q.; White, P.J.; Li, T.; Li, B.; Chen, L.; Li, H.; et al. Loss of organic carbon in suburban soil upon urbanization of Chengdu megacity, China. Sci. Total Environ. 2021, 785, 1-10. [CrossRef]

6. Chen, M.X.; Liu, W.D.; Tao, X.L. Evolution and assessment on China's urbanization 1960-2010: Under-urbanization or overurbanization? Habitat Int. 2013, 38, 25-33. [CrossRef]

7. National Bureau of Statistics of China. China Statistical Yearbook; China Statistics Press: Beijing, China, 2017. (In Chinese)

8. Lin, Y.; Alfred, M.W. Urbanization, land development, and land financing: Evidence from Chinese cities. J. Urb. Aff. 2014, 36, 354-368.

9. Wang, X.R.; Eddie Hui, C.M.; Sun, J.X. Population migration, urbanization and housing prices: Evidence from the cities in China. Habitat Int. 2017, 66, 49-56. [CrossRef]

10. Liang, W.; Yang, M. Urbanization, economic growth and environmental pollution: Evidence from China. Sustain. Comput. Inform. Syst. 2019, 21, 1-9. [CrossRef]

11. Li, B.; Chen, C.; Hu, B. Governing urbanization and the New Urbanization Plan in China. Environ. Urb. 2016, $28,515-534$. [CrossRef]

12. Wang, X.-R.; Hui, E.C.-M.; Choguill, C.; Jia, S.-H. The new urbanization policy in China: Which way forward? Habitat Int. 2015, 47, 279-284. [CrossRef]

13. Liu, Y.; Zhou, G.; Liu, D.; Yu, H.; Zhu, L.; Zhang, J. The interaction of population, industry and land in process of urbanization in China: A case study in Jilin province. Chin. Geogr. Sci. 2018, 28, 529-542. [CrossRef]

14. Huang, L.; Yang, P.; Zhang, B.; Hu, W. Spatio-temporal coupling characteristics and the driving mechanism of population-landindustry urbanization in the Yangtze River Economic Belt. Land 2021, 10, 400. [CrossRef]

15. Chen, M.X.; Liu, W.D.; Lu, D.D. Challenges and the way forward in China's new-type urbanization. Land Use Policy 2016, 55, 334-339. [CrossRef]

16. Geng, B.; Zhang, X.; Liang, Y.; Bao, H.; Skitmore, M. Sustainable land financing in a new urbanization context: Theoretical connotations, empirical tests and policy recommendations. Resour. Conserv. Recycl. 2018, 128, 336-344. [CrossRef]

17. Han, X.; Xia, X.; Zhao, M.; Xu, K.; Li, X. Synergistic effects between financial development and improvements in new-type urbanization: Evidence from China. Emerg. Mark. Financ. Trade 2020, 56, 2055-2072. [CrossRef]

18. Shi, L.; Cai, Z.; Ding, X.; Di, R.; Xiao, Q. What factors affect the level of green urbanization in the Yellow River Basin in the context of new-type urbanization? Sustainability 2020, 12, 2488. [CrossRef]

19. Yang, K.Z. New urbanization and coordinated regional development. Chinese J. Urb. Environ. Stud. 2019, 7, 1-8. [CrossRef] 
20. Hu, B.L.; Chen, C.L. New urbanisation under globalisation and the social implications in China. Asia Pacific Policy Stud. 2015, 2, 34-43. [CrossRef]

21. Crankshaw, O.; Borel-Saladin, J. Causes of urbanisation and counter-urbanisation in Zambia: Natural population increase or migration? Urb. Stud. 2019, 56, 2005-2020. [CrossRef]

22. Jiang, T.-B.; Deng, Z.-W.; Zhi, Y.-P.; Cheng, H.; Gao, Q. The effect of urbanization on population health: Evidence from China. Front. Pub. Health 2021, 9, 1-11. [CrossRef]

23. Wang, X. Relationship between population urbanization and urban sprawl across different city sizes in China. Environ. Urb. ASIA 2021, 12, 202-219. [CrossRef]

24. Shang, J.; Li, P.; Li, L.; Chen, Y. The relationship between population growth and capital allocation in urbanization. Technol. Forecast. Soc. Chang. 2018, 135, 249-256. [CrossRef]

25. Fischer, G.; Winiwarter, W.; Cao, G.Y.; Ermolieva, T.; Hizsnyik, E.; Klimont, Z.; Wiberg, D.; Zheng, X.Y. Implications of population growth and urbanization on agricultural risks in China. Popul. Environ. 2012, 33, 243-258. [CrossRef]

26. Ashraf, M.; Dewan, Y.Y. Land use and land cover change in Greater Dhaka, Bangladesh: Using remote sensing to promote sustainable urbanization. Appl. Geogr. 2009, 29, 390-401.

27. Wu, J.; Cheng, D.; Xu, Y.; Huang, Q.; Feng, Z. Spatial-temporal change of ecosystem health across China: Urbanization impact perspective. J. Cleaner Prod. 2021, 326, 1-14. [CrossRef]

28. Zhang, G.L.; Zhang, N.; Liao, W.M. How do population and land urbanization affect $\mathrm{CO}_{2}$ emissions under gravity center change? A spatial econometric analysis. J. Clean. Prod. 2018, 202, 510-523. [CrossRef]

29. Zhang, Y.; Su, Z.; Li, G.; Zhuo, Y.; Xu, Z. Spatial-temporal evolution of sustainable urbanization development: A perspective of the coupling coordination development based on population, industry, and built-up land spatial agglomeration. Sustainability 2018, 10, 1766. [CrossRef]

30. Zhang, H.Y. China's new urbanization theory and strategic innovation. Sociol. Stud. 2013, 28, 1-14. (In Chinese)

31. Shen, M.Y.; Zhang, J.X. China's rural transformation and revival in the context of new urbanization. City Plan. Rev. 2015, 39, 30-34. (In Chinese)

32. Xu, L.; Cao, H.H. From measure to guidance: Galactic model of new-type urbanization and its evaluation system. J. Pub. Manag. 2014, 11, 65-74. (In Chinese)

33. Wang, F.; Zhang, F.; Lin, X.Y.; Shi, T.W.; Chen, H.T. Study on coupling coordination degree among "population, land, economic and society" urbanization in the Yangtze River Delta region. J. Ind. Technol. Econ. 2018, 37, 45-52. (In Chinese)

34. Li, X.; Li, X.X.; Ou, M.H. Evaluation of urbanization development coordination and analysis of regional disparities in Jiangsu province. Hum. Geogr. 2012, 27, 50-54. (In Chinese)

35. Li, X.G.; Sun, Y. The dynamic effect of population, land, economic urbanization. Econ. Prob. 2018, 3, 106-111. (In Chinese)

36. Zhang, X.J.; Xu, W.X.; Liu, C.J. Spatiotemporal disparity of coupling coordination of economic-land-population-society urbanization in Guangdong-Hong Kong-Macao region and its influencing factors. Inq. Econ. Issues 2019, 10, 54-64. (In Chinese)

37. Chen, Y.; Tian, W.T.; Ma, W.B.; Gu, J.L.; Ma, Z.H. Analysis on spatiotemporal differentiation and influence factors of coordination degree between population urbanization and land urbanization based on ESDA-GWR: A case study of the central plain urban agglomeration. Chinese J. Agric. Resour. Reg. Plan. 2020, 41, 88-99. (In Chinese)

38. Cui, X.F.; Zhang, G.H.; Li, F. A study on spatial differentiation of land intensive use potential: Based on the perspective of "population-economic" dual driving model of land urbanization. East China Econ. Manag. 2016, 30, 62-67. (In Chinese)

39. Wu, Y.F.; Liu, Y.S.; Li, Y.R. Spatio-temporal coupling of demographic-landscape urbanization and its driving forces in China. Acta Geogr. Sin. 2018, 73, 1865-1879. (In Chinese)

40. Zhu, G.L.; Zou, W.; Wang, X.Q. Comparison of economic structure on the coordinated development between population and land urbanization. China Popul. Resour. Environ. 2018, 28, 93-104. (In Chinese)

41. Wu, Y.; Cui, Z.X.; Hu, C. Does the new urbanization influence air quality in China? Front. Environ. Sci. 2021, 9, 1-14. [CrossRef]

42. Jin, D.; Dai, L.L. Temporal and spatial characteristics and driving factors of coordination development between population urbanization and land urbanization. China Land Sci. 2021, 35, 74-84. (In Chinese)

43. Daniel, R.; Alois, H. EU cohesion policy and spatial economic growth: Trajectories in economic thought. Eur. Plan. Stud. 2020, 28, 2116-2133.

44. Alacevich, M. Early development economics debates revisited. J. Hist. Econ. Thought 2011, 33, 145-171. [CrossRef]

45. Sun, X.; Zhang, Z. Coupling and coordination level of the population, land, economy, ecology and society in the process of urbanization: Measurement and spatial differentiation. Sustainability 2021, 13, 3171. [CrossRef]

46. Raffaele, L.; Giovanni, S. Nature-based solutions: Settling the issue of sustainable urbanization. Environ. Res. 2019, 172, 394-398.

47. Lv, T.; Wang, L.; Zhang, X.; Xie, H.; Lu, H.; Li, H.; Liu, W.; Zhang, Y. Coupling coordinated development and exploring its influencing factors in Nanchang, China: From the perspectives of land urbanization and population urbanization. Land 2019, 8, 178. [CrossRef]

48. Lin, Y.; Li, Y.; Ma, Z. Exploring the interactive development between population urbanization and land urbanization: Evidence from Chongqing, China (1998-2016). Sustainability 2018, 10, 1741. [CrossRef]

49. Wang, Y.; Geng, Q.; Si, X.; Kan, L. Coupling and coordination analysis of urbanization, economy and environment of Shandong Province, China. Environ. Dev. Sustain. 2021, 23, 10397-10415. [CrossRef] 
50. Xu, X.; Peng, H.; Xu, Q.; Xiao, H.; Benoit, G. Land changes and conflicts coordination in coastal urbanization: A case study of the Shandong Peninsula in China. Coastal Manag. 2009, 37, 54-69. [CrossRef]

51. Roshni, T.; Kumari, N.; Renji, R.; Drisya, J. Modelling land surface temperature using gamma test coupled wavelet neural network. Adv. Environm. Res. 2017, 6, 265-279.

52. Feng, Q.; Wu, S.; Du, Y.; Xue, H.; Xiao, F.; Ban, X.; Li, X. Improving neural network prediction accuracy for PM10 individual air quality index pollution levels. Environ. Eng. Sci. 2013, 30, 725-732. [CrossRef]

53. Dunea, D.; Pohoata, A.; Iordache, S. Using wavelet-feedforward neural networks to improve air pollution forecasting in urban environments. Environ. Monit. Assess 2015, 187, 477-493. [CrossRef] [PubMed]

54. Wan, J.; Zhang, L.; Yan, J.; Wang, X.; Wang, T. Spatial-temporal characteristics and influencing factors of coupled coordination between urbanization and eco-environment: A case study of 13 urban agglomerations in China. Sustainability 2020, $12,8821$. [CrossRef]

55. Qi, X.; Han, Y.; Kou, P. Population urbanization, trade openness and carbon emissions: An empirical analysis based on China. Air Qual. Atmos. Health 2020, 13, 519-528. [CrossRef]

56. Anser, M.K.; Alharthi, M.; Aziz, B.; Wasim, S. Impact of urbanization, economic growth, and population size on residential carbon emissions in the SAARC countries. Clean Techn. Environ. Policy 2020, 22, 923-936. [CrossRef]

57. The Land Survey Results Sharing Application Service Platform of the Ministry of Natural Resources of PRC. Available online: https://tddc.mnr.gov.cn/ (accessed on 10 January 2022).

58. Li, Z.G.; Wang, J.; Che, S. Effects of land urbanization on spatial emission reduction: Internal mechanism and China experience. Stat. Res. 2021, 38, 89-104. (In Chinese)

59. Chen, J.; Gao, M.; Cheng, S.; Hou, W.; Song, M.; Liu, X.; Liu, Y.; Shan, Y. County-level $\mathrm{CO}_{2}$ emissions and sequestration in China during 1997-2017. Sci. Data 2020, 7, 391. [CrossRef] [PubMed]

60. Zhang, Y.G. Impact of urban and rural household consumption on carbon emissions in China. Econ. Syst. Res. 2013, 25, 287-299. [CrossRef]

61. Wang, R.; Li, F.; Hu, D.; Li, B. Understanding eco-complexity: Social-economic-natural complex ecosystem approach. Ecol. Complex. 2011, 8, 15-29. [CrossRef]

62. He, B.-J.; Zhao, D.-X.; Zhu, J.; Darko, A.; Gou, Z.-H. Promoting and implementing urban sustainability in China: An integration of sustainable initiatives at different urban scales. Habitat Int. 2018, 82, 83-93. [CrossRef]

63. He, B.-J.; Zhu, J.; Zhao, D.-X.; Gou, Z.-H.; Qi, J.-D.; Wang, J. Co-benefits approach: Opportunities for implementing sponge city and urban heat island mitigation. Land Use Policy 2019, 86, 147-157. [CrossRef]

64. Zhao, D.; Zhao, X.; Khongnawang, T.; Arshad, M.; Triantafilis, J. A Vis-NIR spectral library to predict clay in Australian cotton growing soil. Soil Sci. Soc. Am. J. 2019, 82, 1347-1357. [CrossRef]

65. Gao, C.; Tao, S.; He, Y.; Su, B.; Sun, M.; Mensah, I.A. Effect of population migration on spatial carbon emission transfers in China. Energy Policy 2021, 156, 1-13. [CrossRef]

66. Liu, W. EKC test study on the relationship between carbon dioxide emission and regional economic growth. Carb. Manag. 2020, 11, 415-425. [CrossRef]

67. Lv, L.G.; Wu, Z.P.; Wang, J.X.; Wu, S.H.; Zhou, S.L. Soil carbon dioxide efflux responds to land-use changes in the sub-urban regions of Nanjing, China. Appl. Ecol. Environ. Res. 2016, 14, 21-32. [CrossRef]

68. Hepburn, C.; Qi, Y.; Stern, N.; Ward, B.; Xie, C.; Zenghelis, D. Towards carbon neutrality and China's 14th Five-Year Plan: Clean energy transition, sustainable urban development, and investment priorities. Environ. Sci. Ecotechnol. 2021, 8, 100130. [CrossRef] 